\title{
Ecological niche modelling and prioritizing areas for species reintroductions
}

\author{
Enrique Martínez-Meyer, A. Townsend Peterson, Jorge I. Servín and Lloyd F. Kiff
}

\begin{abstract}
Species reintroduction programmes, in prioritizing areas for reintroductions, have traditionally used tools that include measures of habitat suitability and evaluations of area requirements for viable populations. Here we add two tools to this approach: evaluation of ecological requirements of species and evaluation of future suitability for species facing changing climates. We demonstrate this approach with two species for which reintroduction programmes are in the planning stages in Mexico: California condor Gymnogyps californianus and Mexican wolf Canis lupus baileyi. For the
\end{abstract}

condor, we identify three areas clustered in the Sierra San Pedro Mártir, Baja California; for the wolf, we identify a string of suitable sites along the Sierra Madre Occidental of western Mexico. We discuss the limitations of this approach, identifying ways in which the models illustrated could be made more realistic and directly useful to reintroduction programmes.

Keywords California condor, Canis lupus baileyi, ecological niche modelling, Gymnogyps californianus, Mexican wolf, reintroduction.

\section{Introduction}

One of the aims of biodiversity conservation is to avoid loss of species. The best approach preserves natural systems prior to perturbation or damage by human activities. However, conservation action usually begins after species have been extirpated locally or regionally, leaving communities not representative of their original state. Worse still, certain species are extirpated consistently at the initiation of human activity (Patterson, 1987), placing those species in danger of global extinction.

Captive breeding programmes and reintroductions have thus become a key step in avoiding extinctions, as well as for reconstructing natural communities perturbed by human activities. The question of how to define success in these programmes remains open, although the objective is clearly long-term persistence without the need for intervention and management

Enrique Martínez-Meyer Departamento de Zoología, Instituto de Biología, Universidad Nacional Autónoma de México, Circuito Exterior s/n, Ciudad Universitaria, Mexico City 04510, Mexico.

A. Townsend Peterson (Corresponding author) Natural History Museum, The University of Kansas, Lawrence, Kansas 66045, USA. E-mail town@ku.edu

Jorge I. Servín Departamento de Desarrollo Sustentable, Instituto de Ciencias Sociales, Universidad Juárez del Estado de Durango, Apdo. Postal 123, Durango 34001, Mexico

Lloyd F. Kiff Peregrine Fund, 5668 West Flying Hawk Lane, Boise Idaho 83709, USA.

Received 16 March 2005. Revision requested 8 December 2005. Accepted 29 March 2006.
(Seddon, 1999). Recent meta-analyses have indicated three factors emerging as key for successful reintroductions (Wolf et al., 1998): (1) habitat quality of release area, (2) release site relative to historical distribution of the species, and (3) number of individuals released.

Reintroductions generally involve analysis, planning, and selection of optimal areas. Such analyses have taken two paths: (1) population viability analysis (PVA) to determine minimum area requirements and selection of sites by extent (Howells \& Edwards-Jones, 1997; Marshall \& Edwards-Jones, 1998; Merrill et al., 1999; South et al., 2000), or (2) habitat suitability analysis, in which geographical information system analysis is used to refine identification of potential sites via known features of optimal habitat, areas of minimum mortality, or areas of maximum prey availability (Bright \& Smithson, 2001; Cramer \& Portier, 2001).

These strategies, however, have drawbacks. PVA models are generally not spatially explicit, and thus do not take into account complexities of real world landscapes. Habitat suitability models depend critically on knowledge of the natural history of the species involved. When reintroductions extend beyond well known mammals to the broader suite of species that compose natural communities, the fine details of species' natural histories are often unknown. The uncertain basis for refining selection of areas for reintroductions beyond simply extent of known distributions may therefore select areas of uncertain quality. Finally, no prior effort has considered longer term considerations of likely climate change effects on suitability of areas for species' reintroductions. 
Here, we refine reintroduction planning via tools from ecological niche modelling (Peterson et al., 2002b). Bright \& Smithson (2001) suggested that reintroductions can be compared with species' invasions. We accept this analogy, but in a different sense: whereas Bright \& Smithson focused on establishment and spread, we consider niche suitability of the region for the species (Peterson \& Vieglais, 2001; Peterson, 2003a). This step, which Bright \& Smithson subsumed in 'establishment,' is nevertheless key in making an invasion, or reintroduction, successful (Wolf et al., 1998). Moreover, the techniques we apply are broadly applicable, including to species so poorly known biologically that habitat suitability approaches would not be applicable (Peterson et al., 2002b). We illustrate this approach with the examples of the California condor Gymnogyps californianus and Mexican wolf Canis lupus baileyi in Mexico, for which reintroduction programmes are in the planning stages.

\section{Methods}

\section{Input data}

For the condor large quantities (1,970 unique localities) of georeferenced occurrence data were provided by the authors of a previous analysis (Stoms et al., 1993), including data from museum specimens, historical sightings, and recent sightings of the species prior to its extinction in the wild and subsequent reintroduction in California. For the wolf, 26 occurrences were assembled from museum collections' databases (US National Museum of Natural History, University of Kansas Natural History Museum, Museum of Vertebrate Zoology, Instituto de Biología of Universidad Nacional Autónoma de México, University of Michigan Museum of Zoology) and six recent auditory records in remote regions (J. Servín, unpubl. data). For wolves, localities were georeferenced to $0.1^{\prime}$ using the 2000 Mexican national census (INEGI, 2002).

Environmental data layers in which ecological niches were modelled included 12 maps summarizing topography (elevation, slope, aspect, topographic index; USGS, 1997) and annual means of climate variables (diurnal temperature range, precipitation, maximum, minimum, and mean temperatures, solar radiation, wet days, and vapour pressure; IPCC, 1999). Environmental data sets were resampled to a pixel resolution of $0.02 * 0.02^{\circ}$ (c. $2 * 2 \mathrm{~km}$ ), for areas within 700 and $500 \mathrm{~km}$ of known occurrences of condors and wolves, respectively.

\section{Ecological Niche Modelling}

Our general approach to modelling species' ecological niches and predicting geographic distributions is described in detail elsewhere (Stockwell \& Peters, 1999), as are previous tests of this modelling technique in anticipating diverse phenomena (Peterson \& Cohoon, 1999; Peterson et al., 2002a; Peterson \& Vieglais, 2001; Stockwell \& Peterson, 2002a,b; Anderson et al., 2003). The ecological niche of a species can be defined as those ecological conditions under which it can maintain populations without immigration (Grinnell, 1917); as such, it is defined in multidimensional environmental space (MacArthur, 1972). Several approaches have been used to approximate ecological niches (Nix, 1986; Austin et al., 1990; Carpenter et al., 1993). Of these, one that has been extensively tested is the Genetic Algorithm for Rule-set Prediction (GARP), which includes several inferential approaches in an iterative, evolutionary computing approach (Stockwell \& Peters, 1999).

All modelling in this study was carried out using GARP (Scachetti-Pereira, 2002). Within the processing of the GARP software, available occurrence points are divided evenly into training and extrinsic test data sets; the former set is again divided evenly into true training data (for model rule development) and intrinsic test data sets (for model rule evaluation and refinement). GARP is designed to work based on presence-only data; absence information is included via sampling of pseudo-absence points from those pixels where the species has not been detected. GARP works in an iterative process of rule selection, evaluation, testing, and incorporation or rejection: firstly, a method is chosen from a set of possibilities (e.g. logistic regression, bioclimatic rules), and is then applied to the training data and a rule developed; rules may evolve by several means (truncation, point changes, crossing-over among rules) to maximize predictivity. Predictive accuracy (for intrinsic use in model refinement) is then evaluated based on 1,250 points resampled from the intrinsic test data and 1,250 pseudo-absence points. Change in predictive accuracy between iterations is used to evaluate whether particular rules should be incorporated into the model, and the algorithm runs either 1,000 iterations or until convergence.

GARP projects ecological niche models onto current landscapes to estimate present day geographical distributions of suitable conditions. For testing, the half of the input occurrence points set aside as extrinsic test data is overlaid, and observed correct predictions tallied. Proportional area predicted present ${ }^{*}$ number of extrinsic test data points is used as a null expectation of successful prediction of points if no non-random association existed between prediction and test points. A $\chi^{2}$ approach $(1 \mathrm{df})$ tests the significance of departure from random expectations, or a binomial probability can 
be used when sample sizes are low (Anderson et al., 2002).

We produced 100 replicate models of each species' ecological niche, from which we filtered 10 best models using the procedure proposed by Anderson et al. (2003) for choosing among replicate models. The procedure is based on the observations that: (1) models vary in quality, (2) variation among models involves inverse relationships between omission error (i.e. leaving out true distributional area) and commission error (i.e. including predictions of presence areas not actually inhabited), and (3) best models are clustered in a region of minimum omission of independent test points and moderate area predicted (an axis directly related to commission error; Anderson et al., 2003). Position relative to the two error axes provides an assessment of the relative accuracy of each model. Hence, to choose the best subsets of models we (1) eliminated all models except the 20 showing lowest omission error based on independent test points, (2) calculated median area predicted present among these low omission models, and (3) identified the 10 models closest to the overall median area predicted.

Our procedures for evaluating likely climate change effects on species' distribution potential are described in detail elsewhere (Peterson et al., 2001). In general, we compared distributions predicted under 1961-1990 climate scenarios with projections for 2040-2070. These crude climate scenarios clearly reduce the detail possible in our results, but serve nevertheless to identify trends in habitat suitability for species in future decades.

The general circulation model used (Carson, 1999; HadCM2, Hadley Centre) includes several scenarios. We assessed both a conservative and a less conservative view of how climates are likely to change using the SRES A2 and B2 scenarios. B2 assumes a more environmentally educated human population with a strong emphasis on regional rather than global development, making it a conservative estimate of climate change. A2 also assumes regional development, but with many regions relying on fossil fuels as the main energy source, maintaining or increasing current greenhouse gas emissions, and is therefore more liberal. Climate data were downscaled to $0.5 * 0.5^{\circ}$ spatial resolution using methods described elsewhere (Peterson et al., 2001). Models developed for presentday climates were projected onto future climate conditions, providing estimates of species' future potential distributions. We averaged predictions resulting from the two future projections to provide a single future potential prediction of distribution for each species.

\section{Post-processing}

Once basic ecological niche models were developed and projected onto current conditions for each species in the form of a raster grid with values ranging from 0 (predicted absence) to 10 (maximum consensus in prediction of presence), we refined predictions using five considerations of habitat suitability, human interference, and climate change:

(1) We inspected areas predicted to be habitable to ensure they reflected the known original (i.e. as of 1800) distribution of the species, and trimmed disjunct areas outside the original range as necessary. Sources for understanding original distributional areas were Hall (1981) for wolves and Kiff (1977) for condors in Mexico.

(2) We reduced predictions to areas of remaining natural vegetation using the most recent land cover map (Instituto de Geografía, 2001). The original 78 classes in this map were reclassified to primary natural vegetation types versus everything else. Predicted areas were reduced to areas currently holding such natural vegetation types.

(3) We weighted the grid from (2) by distance to human presence, which we represented as the combination of roads (paved primary, secondary, and unimproved roads; ESRI, 1993) and towns with $>5,000$ inhabitants (INEGI, 2002). We buffered $(10 \mathrm{~km}$ distance classes $)$ around roads and towns to create a raster coverage summarizing distance $(d)$ to human presence. We used this coverage to weight predictions from (2) as $1-10 / d$ for condors and $1-9 / d$ for wolves (the constant in the numerator simply scales results to reasonable ranges). We rescaled resulting grids from 0 to 10 based on the maximum values of the index.

(4) We weighted the map resulting from (3) by the climate change predictions; this latter had values (c) ranging from 0 (predicted future absence) to 10 (consensus in prediction of future suitability for the species). We used these predictions to weight the map produced in (3) by multiplying by $1-1 / c$. We rescaled the resulting map from 0 to 10 based on maximum values of the index.

(5) Finally, area considerations were included by extracting patch areas (including the eight contiguous surrounding pixels) using FragStats (McGarigal \& Marks, 1995). We identified patches with the highest values resulting from (4) that also had greatest areas, and took those patches as the most appropriate for reintroductions. 


\section{Results}

\section{Condor}

The predicted distribution coincided with the known 1900 range of the species (Kiff, 1977) from southern California south to northern Baja California (Fig. 1). Based on statistical comparisons with extrinsic test data all models produced were significantly more predictive than random models.

For the Mexican portion of the species' crude potential geographic distribution $\left(4.33^{*} 10^{6}\right.$ ha predicted by $>5$ of the 10 best subsets models; Fig. 2a) we reduced the predicted potential distribution to match the distribution of primary vegetation types (Fig. 2b). This reduced
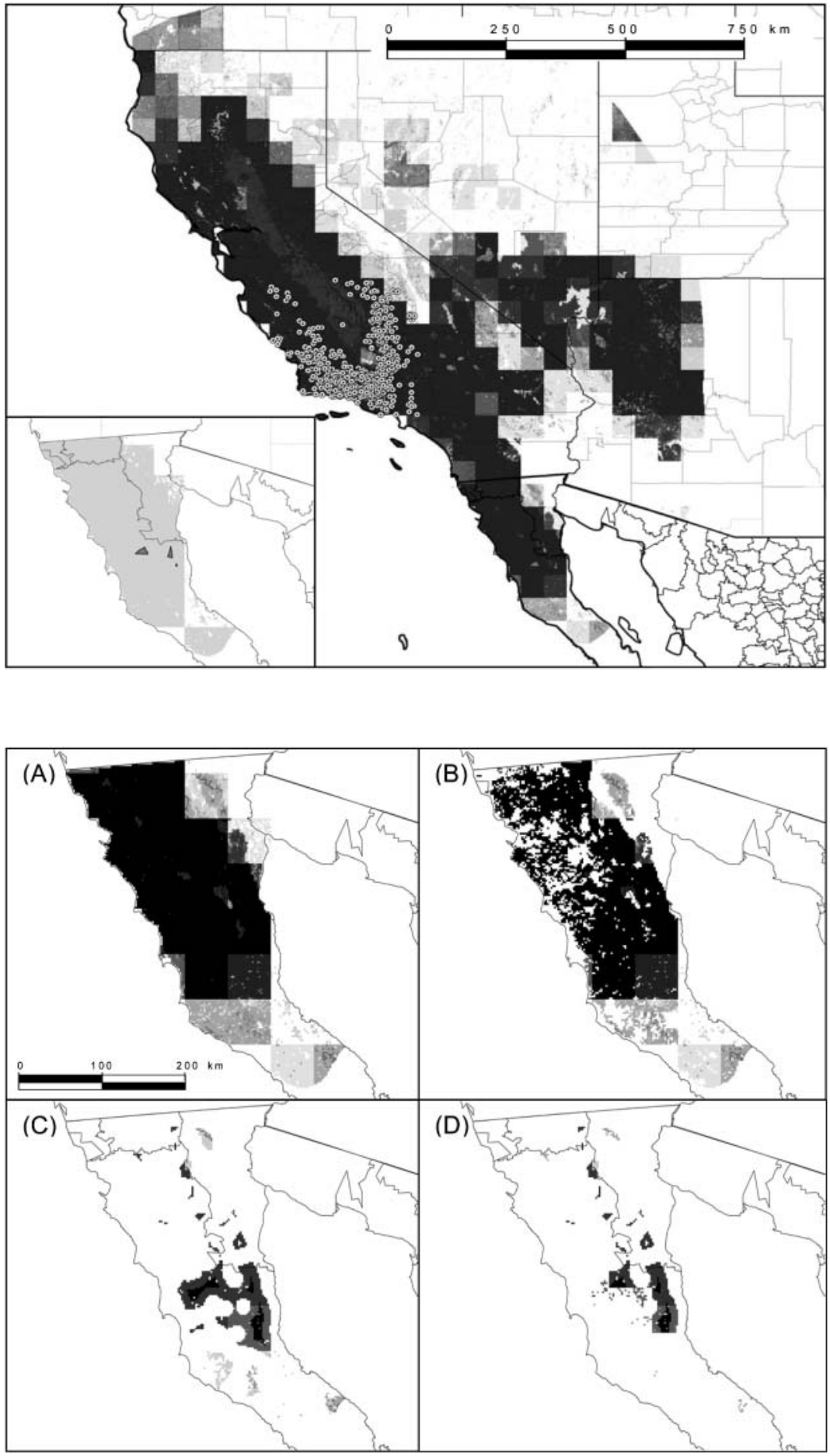

Fig. 1 Known occurrence points (circles) of California condor in southern California, and results of GARP analysis predicting the potential geographic distribution south to northern Baja California. Confidence in prediction of potential presence is shown as a greyscale gradient from white (no confidence) to black (high confidence). Inset shows final areas (dark polygons) selected as optimal for reintroductions: areas predicted habitable at present and not in the future are shown in light grey; areas predicted habitable at present and in the future are in black; areas predicted not habitable at present but that are predicted to become habitable in the future are in dark grey.
Fig. 2 Process of identifying suitable areas for reintroductions of California condors in Mexico: (A) raw GARP prediction that reflects overall suitability of climates and landscapes, (B) cutting by distribution of primary vegetation in the region, $(\mathrm{C})$ weighting by distance to human presence (roads and settlements), and (D) weighting by future climate suitability. Confidence in prediction of potential presence is shown as a greyscale gradient from white (no confidence) to black (high confidence). 


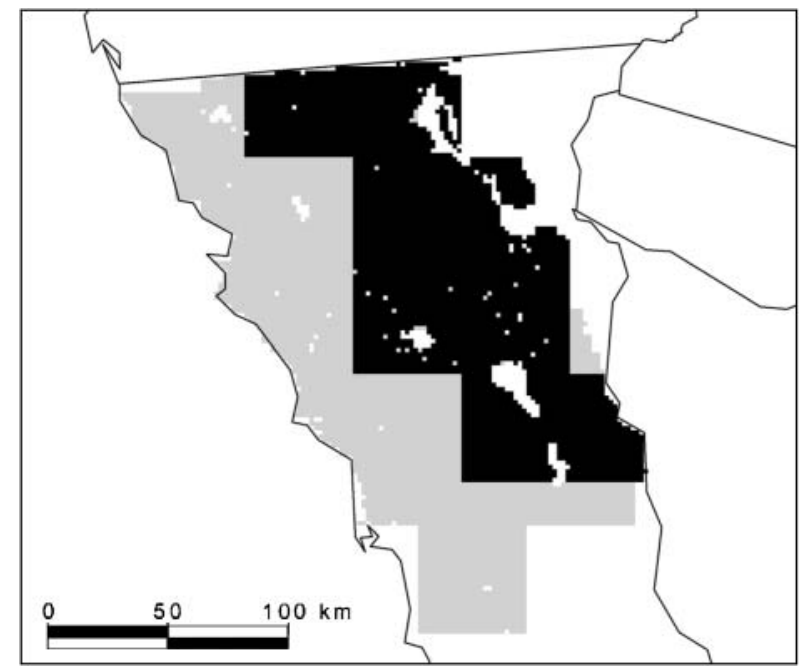

Fig. 3 Prediction of geographic distribution of conditions fitting the ecological niche of California condors in Mexico under changed climate scenarios (average of two climate change scenarios). Area considered habitable at present (Fig. 1) is shown in light grey (where all 10 models agree in prediction of presence). Predictions of future suitability (10 model agreement) are shown in black.

the potential distributional area to $3.31 * 10^{6}$ ha predicted present by $>5$ of the 10 best subsets models $(23.7 \%$ reduction). We then applied the $1-10 / d$ weighting factor to represent distance to human presence (Fig. 2c). Rescaling the suitability measure we lose direct comparability in terms of area; nevertheless, at rescaled grid values of $>5$, we found an area of 660,748 ha $(80.0 \%$ reduction from Fig. $2 b$ ).
Analyses of suitable future climate areas identified a general north-east shift in potentially suitable areas (Fig. 3). We applied the $1-1 / c$ weighting factor to the results of Fig. $2 c$ to represent future changes in climate suitability for the species (Fig. 2d). At rescaled grid values of $>5$, we identified an area of 389,723 ha $(41.0 \%$ reduction from Fig. 2c). Finally, we evaluated the spatial extents of areas predicted suitable for condors at the highest rescaled suitability values (10). These three areas ranged from 989 to 17,310 ha (Fig. 1).

\section{Wolf}

The predicted geographic distribution coincided well with Hall (1981) for the Mexican subspecies. The only major omission was Oaxaca; however, the species is known from the state based on only one record (Goodwin, 1969) and Oaxaca therefore probably always peripheral in the species' distribution.

An initial $61.15^{*} 10^{6}$ ha were predicted as suitable by $>5$ of the 10 best subsets models (Fig. 4a). We reduced this area to primary vegetation areas (Fig. 4b) for a potential distribution area of $37.67 * 10^{6}$ ha predicted present by $>5$ of the 10 best subsets models $(38.4 \%$ reduction). We then applied the $1-9 / d$ weighting factor to represent distance to human presence (Fig. 4c); at rescaled grid values of $>5$ remaining area was 726,526 ha $(98.0 \%$ reduction from Fig. $4 b)$.

The climate change projection indicated a northeast shift in potentially suitable areas (Fig. 5). We applied the $1-1 / c$ weighting factor to represent future

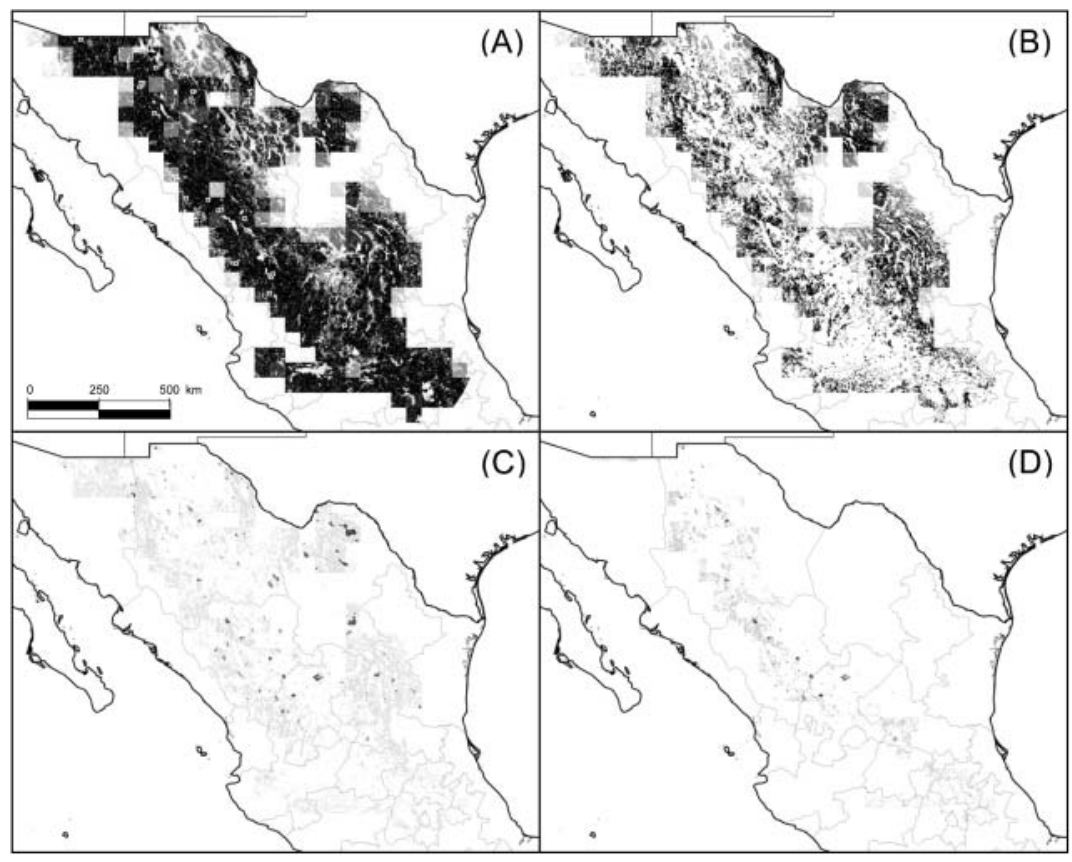

Fig. 4 Process of identifying suitable areas for reintroductions of Mexican wolves in Mexico: (A) raw GARP prediction that reflects overall suitability of climates and landscapes, (B) reducing by distribution of primary vegetation in the region, $(\mathrm{C})$ weighting by distance to human presence (roads and settlements), and (D) weighting by future climate suitability. Confidence in prediction of potential presence is shown as a greyscale gradient from white (no confidence) to black (high confidence). 


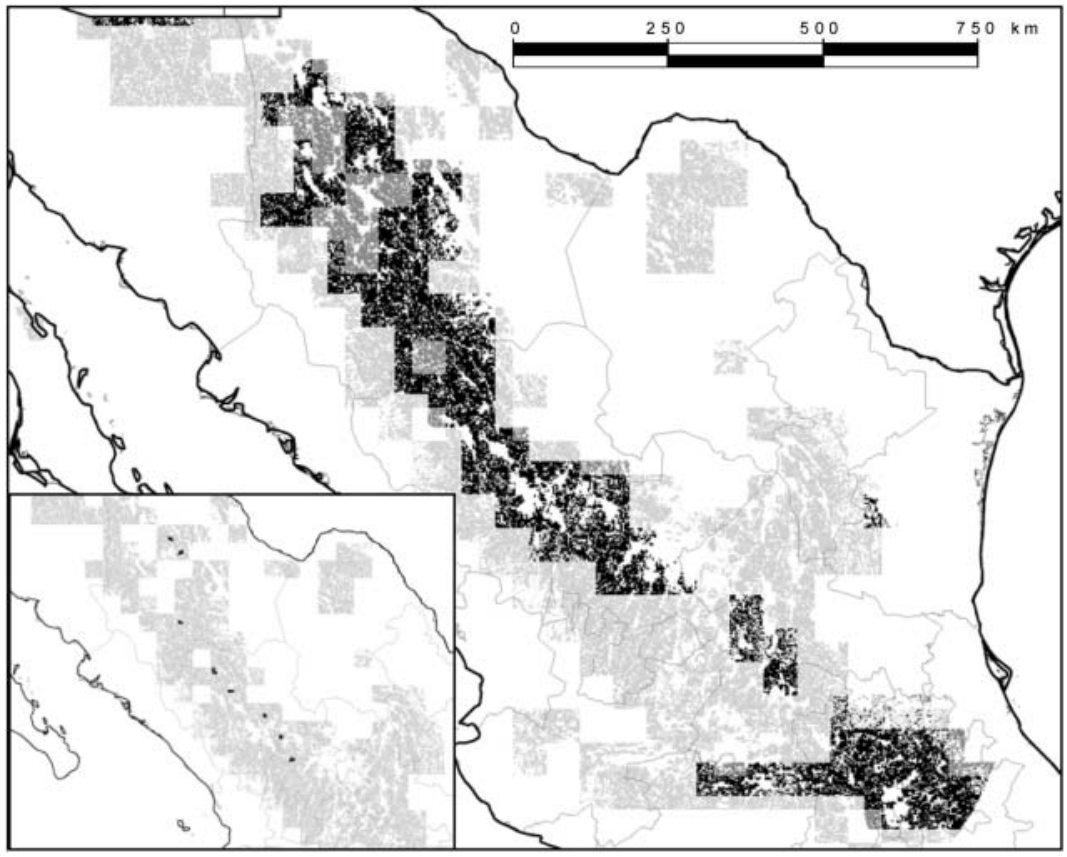

Fig. 5 Prediction of geographic distribution of conditions fitting the ecological niche of Mexican wolves in Mexico under changed climate scenarios (average of two climate change scenarios). Area considered habitable at present (Fig. 4) is shown in light grey. Predictions of future suitability are shown in black (all models agree). Inset shows final areas selected as optimal for reintroductions: areas predicted habitable at present and not in the future are shown in light grey: areas predicted habitable at present and in the future are in black; areas predicted not habitable at present but that are predicted to become habitable in the future are in dark grey. changes in suitability for the species (Fig. 4d). At rescaled grid values of $>5$ we identified an area of 228,492 ha $(68.6 \%$ reduction from Fig. 4c). Finally, we evaluated spatial extents of areas predicted suitable for wolves at the highest rescaled suitability values (8.5); these eight areas ranged from 5,935 to 14,343 ha (Fig. 5).

\section{Discussion}

We emphasize that the examples presented here are intended as illustrations only so that future workers may take advantage of the ideas presented. Numerous improvements are possible, and would be required were these analyses to be used for actual implementation. For example, the habitat suitability measures are artificial, and could be improved considerably for a particular species based on details of its biology. Similarly, our occurrence data did not differentiate between types of occurrences and therefore analyses of more site-specific activities (e.g. nesting, roosting, feeding) could improve models considerably.

The procedure applied takes into account a broad suite of factors in identifying areas suitable for reintroduction programmes. In contrast with most present approaches (Southgate \& Possingham, 1995; Merrill et al., 1999; South et al., 2000; Danks \& Klein, 2002), which generally focus on aspects of habitat suitability and area requirements, we considered more diverse factors. We began modelling the species' ecological niches in terms of climatic and landscape features, which we then reduced to original distribution areas for the species, removing areas of over-prediction owing to effects of history.

We then proceeded to a phase that is analogous to the habitat suitability approaches used by previous authors. We used a simple scheme based only on presence of natural vegetation and distance to human presence. Of course, more complexity could be incorporated, including factors such as prey availability and mortality (Bright \& Smithson, 2001; Cramer \& Portier, 2001). Nevertheless, we provide this step in simple form to illustrate the method.

Next, we considered factors related to longer term persistence, modelling expected changes in suitability of areas in view of changing climates. We based these analyses on methodologies that have been applied broadly to questions of biodiversity conservation (Carey \& Brown, 1994; Huntley et al., 1995; Kadmon \& Heller, 1998; Price, 2000; Peterson et al., 2001; Peterson, 2002a, 2003b; Siqueira \& Peterson, 2003), of which there is a recent global review (Thomas et al., 2004). Areas identified as remaining suitable for the species are those that are projected based on future (2055) climates to match the conditions modelled as presently suitable for the species.

Our selection of specific habitat patches for reintroductions was based on the simple consideration of larger areas being better. However, population viability analyses used by other authors (Lamberson et al., 1994; Nolet \& Baveco, 1996; Marshall \& Edwards-Jones, 1998) could be introduced to refine the process further. In this 
way areas would be selected based on area thresholds that reflect the species' particular area requirements for persistence.

This synthetic approach to prioritization of areas for reintroductions offers several advantages over previous methods. Our first phase addresses the broadest set of considerations: that the area would actually be suitable in terms of climate and other coarse-scale factors for the species. This step has support from previous studies of the predictability of the geographic potential of species' invasions (Peterson, 2003a). Addition of climate change considerations into the prioritization exercise offers a further additional improvement: both current and longer term suitability of an area is incorporated. As such, we believe that this methodology offers a useful framework for more robust identification of areas for reintroductions.

\section{Acknowledgements}

We thank Victor Sánchez-Cordero and Jorge Soberón for insightful discussions of many of the ideas presented here.

\section{References}

Anderson, R.P., Gómez-Laverde, M. \& Peterson, A.T. (2002) Geographical distributions of spiny pocket mice in South America: insights from predictive models. Global Ecology and Biogeography, 11, 131-141.

Anderson, R.P., Lew, D. \& Peterson, A.T. (2003) Evaluating predictive models of species' distributions: criteria for selecting optimal models. Ecological Modelling, 162, 211-232.

Austin, M.P., Nicholls, A.O. \& Margules, C.R. (1990) Measurement of the realized qualitative niche: environmental niches of five Eucalyptus species. Ecological Monographs, 60, 161-177.

Bright, P.W. \& Smithson, T.J. (2001) Biological invasions provide a framework for reintroductions: selecting areas in England for pine marten releases. Biodiversity and Conservation, 10, 1247-1265.

Carey, P.D. \& Brown, N.J. (1994) The use of GIS to identify sites that will become suitable for a rare orchid, Himantoglossum hircinum L., in a future changed climate. Biodiversity Letters, 2, 117-123.

Carpenter, G., Gillison, A.N. \& Winter, J. (1993) DOMAIN: A flexible modeling procedure for mapping potential distributions of animals and plants. Biodiversity and Conservation, 2, 667-680.

Carson, D.J. (1999) Climate modelling: achievements and prospects. Quarterly Journal of the Royal Meteorological Society, 125, 1-27.

Cramer, P.C. \& Portier, K.M. (2001) Modeling Florida panther movements in response to human attributes of the landscape and ecological settings. Ecological Modelling, 140, 51-80.

Danks, F.S. \& Klein, D.R. (2002) Using GIS to predict potential wildlife habitat: a case study of muskoxen in northern Alaska. International Journal of Remote Sensing, 23, 4611-4632.
ESRI (Environmental Systems Research Institute) (1993) Digital Chart of the World. ESRI, Redlands, USA.

Goodwin, G.G. (1969) Mammals from the state of Oaxaca, Mexico, in the American Museum of Natural History. Bulletin of the American Museum of Natural History, 141, 1-269.

Grinnell, J. (1917) Field tests of theories concerning distributional control. American Naturalist, 51, 115-128.

Hall, E.R. (1981) The Mammals of North America. 2nd edition. John Wiley \& Sons, New York, USA.

Howells, O. \& Edwards-Jones, G. (1997) A feasibility study of reintroducing wild boar Sus scrofa to Scotland: are existing woodlands large enough to support minimum viable populations? Biological Conservation, 81, 77-89.

Huntley, B., Berry, P.M., Cramer, W. \& McDonald, A.P. (1995) Modelling present and potential future ranges of some European higher plants using climate response surfaces. Journal of Biogeography, 22, 967-1001.

Instituto de Geografía (2001) Inventario Nacional Forestal 2000. IGUNAM-INEGI, Mexico City, Mexico.

INEGI (Instituto Nacional de Estadística Geografía e Informática) (2002) Localidades de la República Mexicana, 2000. Comisión Nacional para el Conocimiento y Uso de la Biodiversidad, México City, Mexico.

IPCC (Intergovernmental Panel for Climate Change) (1999) Climate Baseline Data: 30-Year Means. University of East Anglia, UK [http:/ /ipcc-ddc.cru.uea.ac.uk/obs/ get_30yr_means.html, accessed 20 February 2005].

Kadmon, R. \& Heller, J. (1998) Modelling faunal responses to climatic gradients with GIS: Land snails as a case study. Journal of Biogeography, 25, 527-539.

Kiff, L.F. (1977) The elusive condor of Baja California. Audubon Imprint, 2, 1-6.

Lamberson, R.H., Noon, B.R., Voss, C. \& McKelvey, K.S. (1994) Reserve design for territorial species: effects of patch size and spacing on the viability of the northern spotted owl Conservation Biology, 8, 185-195.

MacArthur, R. (1972) Geographical Ecology. Princeton University Press, Princeton, USA.

Marshall, K. \& Edwards-Jones, G. (1998) Reintroducing capercaillie (Tetrao urogallus) into southern Scotland: identification of minimum viable populations at potential release sites. Biodiversity and Conservation, 7, 275-296.

McGarigal, K. \& Marks, B.J. (1995) Spatial Pattern Analysis Program for Quantifying Landscape Structure. US Department of Agriculture, Portland, Oregon, USA.

Merrill, T., Mattson, D.J., Wright, R.G. \& Quigley, H.B. (1999) Defining landscapes suitable for restoration of grizzly bears Ursus arctos in Idaho. Biological Conservation, 87, 231-248.

Nix, H.A. (1986) A biogeographic analysis of Australian elapid snakes. In Atlas of Elapid Snakes of Australia (ed. R. Longmore), pp. 4-15. Australian Government Publishing Service, Canberra, Australia.

Nolet, B.A. \& Baveco, J.M. (1996) Development and viability of a translocated beaver Castor fiber population in the Netherlands. Biological Conservation, 75, 125-137.

Patterson, B.D. (1987) The principle of nested subsets and its implications for biological conservation. Conservation Biology, 1, 323-333.

Peterson, A.T. (2003a) Predicting the geography of species' invasions via ecological niche modeling. Quarterly Review of Biology, 78, 419-433.

Peterson, A.T. (2003b) Projected climate change effects on Rocky Mountain and Great Plains birds: generalities 
of biodiversity consequences. Global Change Biology, 9, 647-655.

Peterson, A.T. \& Cohoon, K.C. (1999) Sensitivity of distributional prediction algorithms to geographic data completeness. Ecological Modelling, 117, 159-164.

Peterson, A.T., Sanchez-Cordero, V., Soberon, J., Bartley, J., Buddemeier, R.H. \& Navarro-Siguenza, A.G. (2001) Effects of global climate change on geographic distributions of Mexican Cracidae. Ecological Modelling, 144, 21-30.

Peterson, A.T., Ortega-Huerta, M.A., Bartley, J., SanchezCordero, V., Soberon, J., Buddemeier, R.H. \& Stockwell, D.R.B. (2002a) Future projections for Mexican faunas under global climate change scenarios. Nature, 416, 626-629.

Peterson, A.T., Stockwell, D.R.B. \& Kluza, D.A. (2002b) Distributional prediction based on ecological niche modeling of primary occurrence data. In Predicting Species Occurrences: Issues of Scale and Accuracy (eds J.M. Scott, P.J. Heglund \& M.L. Morrison), pp. 617-623. Island Press, Washington, DC, USA.

Peterson, A.T., Tian, H., Martínez-Meyer, E., Huntley, B., Soberón, J. \& Sánchez-Cordero, V. (in press) Modeling distributional shifts of individual species and biomes. In Biodiversity and Climate Change (eds T.E. Lovejoy \& L. Hannah). Yale University Press, New Haven, USA.

Peterson, A.T. \& Vieglais, D.A. (2001) Predicting species invasions using ecological niche modeling. BioScience, 51, 363-371.

Price, J. (2000) Modeling the potential impacts of climate change on the summer distributions of Massachusetts passerines. Bird Observer, 28, 224-230.

Scachetti-Pereira, R. (2002) Desktop GARP. The University of Kansas, Lawrence, USA [http://www.lifemapper.org/ desktopgarp/, accessed 23 February 2005].

Seddon, P.J. (1999) Persistence without intervention: assessing success in wildlife reintroductions. Trends in Ecology $\mathcal{E}$ Evolution, 14, 503.

Siqueira, M.F.d. \& Peterson, A.T. (2003) Global climate change consequences for cerrado tree species. Biota Neotropica, 3, 2 [http://www.biotaneotropica.org.br/v3n2/pt/ abstract?article+BN00803022003, accessed 25 October 2006].

South, A., Rushton, S. \& Macdonald, D. (2000) Simulating the proposed reintroduction of the European beaver (Castor fiber) to Scotland. Biological Conservation, 93, 103-116.

Southgate, R. \& Possingham, H. (1995) Modeling the reintroduction of the greater bilby Macrotis lagotis using the metapopulation model Analysis of the Likelihood of Extinction (Alex). Biological Conservation, 73, 151-160.

Stockwell, D.R.B. \& Peters, D.P. (1999) The GARP modelling system: problems and solutions to automated spatial prediction. International Journal of Geographic Information Systems, 13, 143-158.

Stockwell, D.R.B. \& Peterson, A.T. (2002a) Controlling bias in biodiversity data. In Predicting Species Occurrences: Issues of Scale and Accuracy (eds J.M. Scott, P.J. Heglund \& M.L. Morrison), pp. 537-546. Island Press, Washington, DC, USA.

Stockwell, D.R.B. \& Peterson, A.T. (2002b) Effects of sample size on accuracy of species distribution models. Ecological Modelling, 148, 1-13.

Stoms, D.M., Davis, F.W., Cogan, C.B., Painho, M.O., Duncan, B.W., Scepan, J. \& Scott, J.M. (1993) Geographic analysis of California Condor sighting data. Conservation Biology, 7, 148-159.

Thomas, C.D., Cameron, A., Green, R.E., Bakkenes, M., Beaumont, L.J., Collingham, Y.C., Erasmus, B.F.N., Ferreira de Siqueira, M., Grainger, A., Hannah, L., Hughes, L., Huntley, B., Van Jaarsveld, A.S., Midgely, G.E., Miles, L., Ortega-Huerta, M.A., Peterson, A.T., Phillips, O.L. \& Williams, S.E. (2004) Extinction risk from climate change. Nature, 427, 145-148.

USGS (United States Geological Survey) (1997) Hydro $1 k$ Elevation Derivative Database. Sioux Falls, USA [http:// edc.usgs.gov/products/elevation/gtopo30/hydro/index. html, accessed 20 February 2005].

Wolf, C.M., Garland, Jr, T. \& Griffith, B. (1998) Predictors of avian and mammalian translocation success: reanalysis with phylogenetically independent contrasts. Biological Conservation, 86, 243-255.

\section{Biographical sketches}

Enrique Martínez-Meyer's main research interests are the ecological biogeography of species, with special emphasis on climate change and evolution of ecological niches, and the ecology of mammals, in particular carnivores.

A. Townsend Peterson is Curator of the Natural History Museum and Biodiversity Research Center, University of Kansas. His research focuses on the ecology and evolutionary history of species' ecological and geographic distributions.

Jorge I. Servín's research interests are in wildlife biology, particularly the ecology of carnivores, and sustainable development. He currently chairs the National Committee for the Recovery of the Mexican Wolf.

Lloyd Kiff is Science Director at the Peregrine Fund. His main research interest is in raptor biology. 